DOI: $10.17805 /$ zpu.2018.3.11

\title{
Динамика отношения московской молодежи к сожительству (на основе эмпирических исследований 2009-2017 гг.)
}

\author{
Д. А. ТИХОМИРОВ
}

РОССИЙСКИЙ ЭКОНОМИЧЕСКИЙ УНИВЕРСИТЕТ ИМ. Г. В. ПЛЕХАНОВА

В статье на основании результатов исследований, проведенных автором в период 2009-2017 гг., рассматривается динамика отношения молодежи г. Москвы к сожительству. Показывается, что установка на брак в молодежной среде сохраняется, но модель брака меняется.

Добрачное сожительство московской молодежи закрепляется в качестве социальной нормы. Это проявляется в либеральном отношении большинства молодых людей к нему, в установке на вступление в сожительство перед браком и его широком распространении (опыт сожительства имеют 33\% опрошенных молодых людей). Проводится анализ изменения отношения к сожительству различных социальных групп (половозрастных и религиозных). Несмотря на закрепление добрачного сожительства у молодежи в качестве социальной нормы, определенная дифференциация отношения к нему в обществе все еще сохраняется. В межпоколенном восприятии сожительства как нормы или отклонения позиция представителей молодого поколения определяется позицией их родителей, которая дифференцируется в зависимости от пола их ребенка. 
Широкое распространение добрачного сожительства не приводит к повышению стабильности института брака. Это должно найти отражение в государственной социальной политике, в которой все отчетливее артикулируется необходимость воссоздания традиционных семейно-брачных ценностей и формулируется зарегистрированный брак с несколькими детьми в качестве социальной нормы.

Ключевые слова: молодежь; сожительство; добрачное сожительство; брак; социальная норма; социальное отклонение; молодежь Москвы

\section{ВВЕАЕНИЕ}

$\mathrm{B}$ 2009 г. нами было проведено исследование восприятия различными социальными группами российского общества добрачных сексуальных отношений молодежи как нормы или отклонения (Тихомиров, 2009; Ауков, Тихомиров, 2012). В результате были установлены факторы, определяющие это восприятие, и сделаны выводы о деструкции нормативности в вопросах половой морали, которая охватила, пусть и в различной степени, даже верующих и старшие поколения. Аиберализация половой морали отразилась на семейно-брачных отношениях. Незарегистрированные супружеские союзы получили широкое распространение в российском обществе (по данным переписи населения 2010 г., их число составило 13\% от всех браков (Вот какие мы ... , 2011: Электронный ресурс), по данным микропереписи населения 2015 г. - 12,4\% (Микроперепись ... , 2015: Электронный ресурс). Сожительство не вытеснило брак, но стало предваряющим его этапом («пробным браком»). Исследование Фонда «Общественное мнение» в 2013 г. показало, что почти каждый третий брачный союз заключается после проверки отношений в сожительстве (Осипова, 2013).

Перемены брачного поведения, усиливающие риск сползания страны в демографическую яму, фокусирует внимание российского общества на семейно-брачной проблематике. Все чаще высшими органами государственной власти артикулируется необходимость воссоздания традиционных семейно-брачных ценностей. Воплощением этого стали концептуальные документы 2014 г., определяющие направление семейной и молодежной политики в стране до 2025 г., в которых в качестве нормативного ориентира обозначена семья, образованная на основе зарегистрированного брака мужчины и женщины, ориентированных на рождение и воспитание нескольких детей, «Основы государственной молодежной политики Российской Федерации на период до 2025 года» (Распоряжение Правительства Российской Федерации от 29 ноября 2014 г. № 2403-р ..., 2014: Электронный ресурс); «Концепция государственной семейной политики в Российской Федерации до 2025 года» (Распоряжение Правительства Российской Федерации от 25 августа 2014 г. № 1618-р ..., 2014: Электронный ресурс). Аругими словами, зарегистрированный брак мужчины и женщины обозначен в качестве формальной нормы, которая уже не всегда соответствует той, которая определяет брачное поведение молодого поколения. В этой связи возникает вопрос: изменилось ли отношение различных групп молодежи к сожительству и их брачное поведение? В раскрытии данной темы видится и цель этой статьи.

Определенный материал для прояснения поставленной проблемы дает проведенное автором в конце 2017 г. среди московской молодежи в возрасте 18-24 лет эмпирическое исследование, инструментарий которого был разработан на основе исследования 2009 г. В качестве основного метода исследования было использовано анкетирование $(\mathrm{N}=358$, среди опрошенных $63 \%$ женщин и $37 \%$ мужчин, так же как и в опросе 2009 г., $\mathrm{N}=533)$, дополнительного - фокус-группа с молодыми москвичами в возрасте 18-22 лет (4 по 5 человек в каждой). Объектом исследования 2009 г. были моло- 
дые люди в возрасте 18-29 лет, тогда как в последнем - 18-24 лет, поэтому данные первого исследования в целях корректного сопоставления были пересчитаны для возрастной категории 18-24 лет. Такой объект исследования был выбран в связи с задачей выявления брачных установок юношей и девушек, только планирующих вступление в брак, чаще всего реализуемое в возрасте 25-34 лет (Российский статистический ..., 2017).

\section{ОТНОШЕНИЕ МОАОАЕЖИ К БРАКУ}

В целом установка на брак среди московской молодежи сохраняется. Большинство $(75 \%)$ юношей и девушек планируют вступить в брак, $11 \%$ - не планируют вступать в брак, а остальные пока не определились. Но торопиться с этим решением молодые люди не собираются. Наиболее предпочтительным возрастом для вступления в брак как для мужчины, так и для женщины респонденты называют 25-29 лет (табл. 1). Отметим гендерные различия в восприятии этого возраста: мужчины значительно чаще женщин обозначают необходимость более раннего замужества. Проведенное фокусгрупповое исследование позволило уточнить эти гендерные отличия, которые заключаются в том, что этот возраст для женщин находится у нижней границы диапазона 25-29 лет, а у мужчин - у верхней, нередко несколько ее превышая. Соответственно, изменяются представления об оптимальном возрасте женщины при рождении первого ребенка. Таким возрастом молодые люди считают 25-29 лет - 60\% опрошенных, 18-24 года - 22\%, 30-34 года - 9\%. Причем в последней возрастной категории проявились наиболее существенные гендерные различия $(3,5 \%$ мужчин против $11,0 \%$ женщин).

Таблища 1

ПРЕАСТАВАЕНИЕ МОАОАЕЖИ О НАИБО АЕ ПРЕАПОЧТИТЕАЬНОМ ВОЗРАСТЕ ВСТУПАЕНИЯ В БРАК, \%

Table 1

REPRESENTATION OF YOUTH ABOUT THE MOST PREFERABLE AGE OF MARRIAGE, IN \%

\begin{tabular}{|c|c|c|c|c|c|c|}
\hline \multirow{2}{*}{$\begin{array}{c}\text { Предпочтительный } \\
\text { возраст вступления } \\
\text { в брак, лет }\end{array}$} & \multicolumn{2}{|c|}{ Аля мужчин } & \multicolumn{2}{|c|}{ Аля женщин } & \multicolumn{2}{|c|}{ Bcero } \\
\hline & $\begin{array}{c}\text { мужской } \\
\text { пол }\end{array}$ & $\begin{array}{c}\text { женский } \\
\text { пол }\end{array}$ & $\begin{array}{c}\text { мужской } \\
\text { пол }\end{array}$ & $\begin{array}{c}\text { женский } \\
\text { пол }\end{array}$ & $\begin{array}{c}\text { женский } \\
\text { пол }\end{array}$ & $\begin{array}{c}\text { женский } \\
\text { пол }\end{array}$ \\
\hline $18-24$ & 5,1 & 6,3 & 39,3 & 28,4 & 5,9 & 32,3 \\
\hline $25-29$ & 66,7 & 71,8 & 44,6 & 63,7 & 70,0 & 57,0 \\
\hline $30-34$ & 15,4 & 13,4 & 3,6 & 2,9 & 14,1 & 3,2 \\
\hline 35 и более & 3,8 & 1,4 & - & - & 2,3 & - \\
\hline $\begin{array}{c}\text { Затрудняюсь } \\
\text { ответить }\end{array}$ & 9,0 & 7,0 & 12,5 & 4,9 & 7,7 & 7,6 \\
\hline
\end{tabular}

ОТНОШЕНИЕ МОАОАЕЖИ К СОЖИТЕАЬСТВУ

И ОСНОВНЫЕ ФАКТОРЫ ЕГО АИФФЕРЕНЦИАЦИИ

Повышение возраста вступления в брак приводит к изменению модели добрачного поведения молодого поколения. Сожительство молодежи закрепляется в качестве социальной нормы, что проявляется в отношении, установках и поведении молодых людей. Последовательно продемонстрируем произошедшие изменения обозначенных 
показателей за период 2009-2017 гг., начав с отношения представителей молодого поколения к сожительству.

На вопрос «Как Вы относитесь к сожительству с партнером без официальной регистрации брака?» 72\% респондентов ответили, что относятся к сожительству положительно (из них положительно - 41\%, скорее положительно - 31\%), тогда как противоположного мнения придерживаются только 19\% (из них отрицательно - 6\%, скорее отрицательно - 13\%). В опросе 2009 г. шкала была сформулирована иначе (осуждаю - 12,0\%; и да, и нет - 48,5\%; одобряю - 39,5\%), тем не менее сопоставление крайних позиций этих опросов (осуждаю / отрицательно и одобряю / положительно) показывает двукратное уменьшение за обозначенный период доли отрицательных оценок (с $12 \%$ до 6\%).

Сожительство воспринимается в качестве социальной нормы для представителей обоих полов. Вместе с тем нельзя не отметить значительные гендерные различия, которых практически не было в опросе 2009 г. Так, среди молодых мужчин положительно относятся к сожительству $83 \%$ (из них положительно - 52\%, скорее положительно $30 \%$ ), а среди женщин - $67 \%$ (из них положительно - 35\%, скорее положительно $32 \%$ ), отрицательно - $11 \%$ мужчин (из них отрицательно - 2\%, скорее отрицательно - $9 \%$ ) и $23 \%$ женщин (из них отрицательно - $8 \%$, скорее отрицательно - $15 \%$ ).

Сожительство, как показало исследование 2009 г., воспринимается как норма во всех возрастных группах, в том числе старшими поколениями - отцами и дедами, хотя некоторые отличия все же присутствуют и связаны они с усилением отрицательных оценок в старших возрастных группах. Если в 2009 г. мы опрашивали представителей различных поколений, выявляя их отношение к сожительству молодежи, то в 2017 г. акцент был сделан на выяснение мнения молодых людей об отношении их родителей к сожительству. Полученные данные также показали, что сожительство рассматривается и старшим поколением как норма, хотя некоторые межпоколенческие различия в этом восприятии сохраняются, проявляясь в более либеральных взглядах представителей молодого поколения. Большая часть родителей респондентов одобряют сожительство молодежи. Так, 46\% опрошенных молодых людей отметили, что их родители положительно относятся к сожительству, отрицательно - 28\% (табл. 2). В ходе

ОТНОШЕНИЕ К СОЖИТЕ $А$ СВУ

Таблица 2

РОАИТЕАЕЙ РЕСПОНАЕНТОВ, В \%

Table 2

THE ATTITUDE TO THE COHABITATION

OF THE PARENTS OF RESPONDENTS, IN \%

\begin{tabular}{|l|c|c|c|}
\hline \multirow{2}{*}{$\begin{array}{c}\text { Как Ваши родители относятся к тому, } \\
\text { что ньне молодые люди нередко живут вместе } \\
\text { без официальной регистрачии брака? }\end{array}$} & \multicolumn{2}{|c|}{ Пол } & \multirow{2}{*}{ Всего } \\
\cline { 2 - 3 } & мужской & женский & \\
\hline Положительно & 17 & 18 & 18 \\
Скорее положительно & 32 & 26 & 28 \\
Скорее отрицательно & 14 & 22 & 19 \\
Отрицательно & 3 & 12 & 9 \\
Затрудняюсь ответить & 34 & 21 & 26 \\
\hline
\end{tabular}


опроса 2017 г. в межпоколенном отношении было выявлено два важных аспекта. Вопервых, отношение родителей к сожительству дифференцируется полом их ребенка. Мужчины значительно чаще женщин отмечают либеральную позицию своих родителей, что особенно ярко проявляется в разрезе отрицательных оценок. Если положительно оценивают сожительство родители 49\% мужчин и 44\% женщин, то отрицательно - только 17\% мужчин и 34\% женщин. Во-вторых, отношение молодых людей к сожительству определяется позицией их родителей (табл. 3).

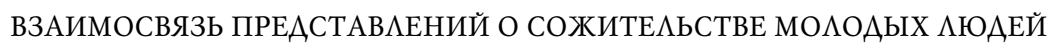 И ИХ РОАИТЕАЕЙ, \% (ПО СТРОКЕ)}

Таблица 3

Table 3

INTERRELATION OF REPRESENTATIONS ABOUT COHABITATION OF YOUNG PEOPLE

AND THEIR PARENTS, IN \% (ON LINE)

\begin{tabular}{|c|c|c|c|c|}
\hline \multirow{2}{*}{$\begin{array}{c}\text { Как Вы относитесь } \\
\text { к сожительству с партнером } \\
\text { без офичиальной регистрачии } \\
\text { брака? }\end{array}$} & \multicolumn{4}{|c|}{$\begin{array}{c}\text { Как Ваши родители относятся к тому, } \\
\text { что ныне молодые люди нередко живут вместе } \\
\text { без официльной регистрачии брака? }\end{array}$} \\
\hline & положительно & скорее & $\begin{array}{c}\text { скорее } \\
\text { отричательно }\end{array}$ & отрицательно \\
\hline положительно & 34 & 37 & 9 & - \\
\hline скорее положительно & 7 & 35 & 18 & 5 \\
\hline скорее отрицательно & 6 & 3 & 39 & 30 \\
\hline отрицательно & 6 & - & 50 & 44 \\
\hline Всего & 18 & 28 & 19 & 9 \\
\hline
\end{tabular}

Аифференциация отношения к сожительству определяется не только половозрастными характеристиками, но и религиозными. Между социальными группами религиозных, нерелигиозных и неверующих проявляются значительные отличия в восприятии сожительства. Так, положительно относятся к сожительству соответственно: $65 \%$ религиозных, $79 \%$ нерелигиозных и $80 \%$ неверующих (табл. 4). Тем не менее большинство представителей каждой из этих групп воспринимают сожительство как социальную норму.

Значительные отличия в отношении к сожительству прослеживаются внутри религиозной группы между молодыми последователями православия и ислама. Причем эти отличия заключаются в противоположном восприятии сожительства как социальной нормы или отклонения (табл. 5). За период с 2009 по 2017 г. они стали более существенными, поскольку либеральное отношение к сожительству среди молодых православных усилилось (если положительные оценки увеличились с $34 \%$ до $39 \%$, то отрицательные - сократились с $14 \%$ до 6\%), тогда как взгляды мусульманской молодежи практически не изменились.

Итак, если для большинства православных молодых людей сожительство стало нормой, то для мусульман остается отклонением, так же как и для воцерковленных христиан (для 80\% исповедующихся и причащающихся один раз в неделю и для $60 \%$ совершающих эти таинства один раз в месяц остается важным вступление в брак без практики добрачного сожительства, см.: Тихомиров, 2017). 
ОТНОШЕНИЕ К СОЖИТЕАЬСТВУ В ЗАВИСИМОСТИ ОТ ВЕРЫ В БОГА, \%

Таблииа 4

THE ATTITUDE TO COHABITATION DEPENDING ON FAITH IN GOD, IN \%

\begin{tabular}{|c|c|c|c|}
\hline \multirow{2}{*}{$\begin{array}{c}\text { Отношение } \\
\kappa \text { сожительству }\end{array}$} & \multicolumn{3}{|c|}{ Верите ли Вы в существование бога? } \\
\hline & $\begin{array}{c}\text { Аа, верю } \\
\text { иринадлежу } \\
\text { крелигии }\end{array}$ & $\begin{array}{c}\text { Аа, верю, но } \\
\text { ни какой религии } \\
\text { не принадлежу }\end{array}$ & Нет, не верго \\
\hline Положительное & 31 & 56 & 41 \\
\hline Скорее положительное & 34 & 23 & 39 \\
\hline Скорее отрицательное & 19 & 8 & 5 \\
\hline Отрицательное & 10 & 3 & 0 \\
\hline Затрудняюсь ответить & 7 & 10 & 16 \\
\hline
\end{tabular}

\section{СОЦИААЬНЫЙ СМЫСА СОЖИТЕАЬСТВА \\ В ПРЕАСТАВАЕНИИ МОАОАЕЖИ}

Аиберальное отношение значительной части молодежи к сожительству определяет их брачные установки и поведение. Несмотря на то что социальная установка на брак сохраняется, модель брачного поведения меняется. Наиболее предпочтительным вариантом организации брачной жизни в молодежной среде является вступление в добрачное сожительство. Так, 81\% (в 2009 г. - 67\%) респондентов считают, что до вступления в официальный брак необходимо пожить в незарегистрированном союзе, проверив свои чувства и отношения (79,3\% юношей и 82,1\% девушек), а каждый третий $(33 \%)$ - уже имеет подобный опыт. Только 7\% (в 2009 г. - 23\%) убеждены в необходимости организации семейной жизни с официального брака $(4,6 \%$ юношей и 8,3\% девушек). Отметим произошедшие в период с 2009 по 2017 г. изменения, показывающие закрепление добрачного сожительства в качестве основной социальной

Таблица 5

ОТНОШЕНИЕ К СОЖИТЕАЬСТВУ ПРАВОС АВНЫХ И МУСУАЬМАН, \% Table 5

THE ATTITUDE TO COHABITATION OF THE ORTHODOX AND MUSLIMS, IN \%

\begin{tabular}{|l|c|c|}
\hline \multirow{2}{*}{$\begin{array}{c}\text { Oтнотение } \\
\text { ксжительству }\end{array}$} & \multicolumn{2}{|c|}{ Религиознал принадлежность } \\
\cline { 2 - 3 } & $\begin{array}{c}\text { Православное } \\
\text { христианство }\end{array}$ & Ислал \\
\hline Положительное & 39 & 20 \\
Скорее положительное & 38 & 10 \\
Скорее отрицательное & 12 & 30 \\
Отрицательное & 6 & 25 \\
Затрудняюсь ответить & 4 & 15 \\
\hline
\end{tabular}


нормы брачного поведения среди молодежи. Но эта норма распространяется только на сожительство, предваряющее брак («пробный брак»), а не заменяющее его вовсе (сожительство как полноценную альтернативу браку рассматривают менее $2 \%$ ). Большинство (57\%) опрошенных воспринимают сожительство как временную форму отношений (2009 г. - 50\%), позволяющую проверить взаимные чувства и совместимость партнеров; 21\% полагают, что это обычный брачный союз, но без штампа в паспорте (2009 г. - 23\%); 15\% видят в нем качественно иной союз, пришедший на смену традиционному браку, со своими преимуществами и недостатками (2009 г. - 9\%).

Период, необходимый для проверки отношений в сожительстве, весьма существенный. Так, 43\% респондентов полагают, что для принятия взвешенного решения о вступлении в брак с партнером требуется опыт проживания в незарегистрированном союзе от года до трех лет, $35 \%$ считают, что для этого требуется от нескольких месяцев до года. Причины трансформации сожительства в брак, выделяемые молодыми людьми (желание стабильности отношений при понимании правильного выбора партнера - 76\%, беременность - 49\%, желание сыграть свадьбу - 37\%), демонстрируют сохранение в сознании молодежи не только значимости ритуальной стороны брака, но и его ассоциации с более стабильной формой брачных отношений.

Основные преимущества сожительства по сравнению с браком респонденты связывают с возможностью: проверить отношения и совместимость с партнером (58\%), разойтись без формальностей и раздела имущества $(57 \%)$, выстроить более свободные отношения (27\%), сберечь финансовые ресурсы, необходимые на свадьбу (20\%). Недостатками же сожительства в представлении молодых людей являются: неуверенность в будущем в связи с нестабильностью сожительства - 44\%, отсутствие полноценного социального статуса мужа / жены в сожительстве - 39\%, отсутствие ответственности и обязательств перед партнером в сожительстве - 36\%, юридическая незащищенность женщины в сожительстве - 28\%, неприятие сожительства социальным окружением - 7\%. Причем в данном вопросе высвечиваются значительные гендерные отличия, проявляемые главным образом в специфике незарегистрированных отношений. Женщины в два раза чаще мужчин акцентируют такие недостатки сожительства, как отсутствие полноценного брачного статуса в сожительстве $(49 \%$ против 22\%), неуверенность в будущем в связи с нестабильностью сожительства (53\% против 27\%), юридическая незащищенность женщины в сожительстве (35\% против $16 \%)$, неприятие таких отношений социальным окружением (8\% против 4\%), и в 3 раза реже мужчин отмечают отсутствие недостатков в сожительстве ( $8 \%$ против $25 \%$ ). Несмотря на обозначенные недостатки незарегистрированных отношений, большая часть респондентов (37\%) полагают, что сожительство в равной степени выгодно как мужчине, так и женщине; $24 \%$ считают, что все зависит от ситуации; $18 \%$ видят большую выгоду мужчин, а 12\% - женщин. Причем в данном вопросе гендерные различия практически не заметны.

\section{ОСОБЕННОСТИ АОБРАЧНОГО ПОВЕАЕНИЯ МОАОАЕЖИ МОСКВЫ}

О том, что сожительство становится социальной нормой, свидетельствует и брачное поведение столичной молодежи. Опыт сожительства имеют $33 \%$ опрошенных молодых людей (2009 г. - 31\%), среди которых 46\% состояли в этом союзе на момент опроса, у $20 \%$ респондентов сожительство закончилось браком, а у $29 \%$ - разрывом отношений. Показательно, что точно такое же число (33\%) молодых людей, имеющих 
опыт сожительства, было получено в ходе исследования молодежи Самарской области и Республики Татарстан ( $\mathrm{N}=484$ молодых людей в возрасте 18-29 лет), проведенного С. В. Явон и К. А. Кудрявцевой в 2016 г. (Явон, Кудрявцева, 2017).

Сожительство, как мы отмечали ранее, вовсе не отменяет брак, а становится предваряющим его этапом. Социальная установка на брак сохраняется и у сожительствующих партнеров: 67\% планировали вступление в брак (2009 г. - 52\%), 8\% хотели это сделать, но столкнулись с нежеланием партнера, не планировали же вступление в брак $25 \%$. Большинство (68\%) респондентов утверждают, что совместно принимали решение о начале своей брачной жизни с сожительства, а не с брака $(70 \%$ женщин и 59\% мужчин). Женщины несколько реже мужчин говорят о том, что это была их инициатива (12\% против $14 \%)$, но значительно чаще отмечают инициативу партнера (16\% против $7 \%$ в в решении данного вопроса.

Обоснование респондентов (был задан открытый вопрос), переживших распад сожительства, причин разрыва незарегистрированного союза высвечивает неподготовленность молодых людей к семейно-брачным отношениям и возникающие в связи с этим трудности освоения социальных ролей мужа / жены. Большинство (примерно 60\% среди ответивших) респондентов мотивировали разрыв отношений несовместимостью с партнером (разные характеры, взгляды на жизнь, брачные отношения и распределение обязанностей), вредные привычки партнера (пьянство, наркомания) отметили 20\%, насилие («партнер поднял руку», «избил») и измену по $10 \%$.

Сожительство, воспринимаемое респондентами как пробный брак, не предполагает рождение в нем детей, которое ассоциируется с официальным браком. За период с 2009 по 2017 г. такая позиция стала все более распространенной. Большинство (79\%) респондентов считают, что дети должны появляться на свет в браке (2009 г. - 64\%), хотя 40\% из них и добавляют, что ситуации в жизни могут быть разные. Причем такая позиция чаще характерна для мужчин, нежели для женщин (47\% против 37\%), которые значительно чаще мужчин связывают рождение детей исключительно с браком (44\% против 30\%). Брачный статус респондентов оказывает значительное влияние на их позицию. Так, 36\% молодых людей, не состоящих в браке, полагают, что детей необходимо рожать в браке, тогда как среди сожителей таких насчитывается 51\%, оговариваются, что ситуации могут быть разные, 43\% первых и 26\% вторых. Только $13 \%$ (2009 г. - 22\%) респондентов считают, что форма брачной организации не влияет на реализацию репродуктивных планов женщины (среди не состоящих в браке так считают $11 \%$, а среди сожителей $-18 \%$ ).

В представлении молодого поколения рождение детей не ассоциируется с сожительством, у которого иное функциональное предназначение. Здесь проходит четкая граница, разделяющая добрачное сожительство и официальный брак. Беременность и рождение ребенка, как было показано выше, воспринимаются респондентами в качестве одной из основных причин официальной регистрации брачных отношений сожительствующими партнерами - 49\%. Именно негативное влияние сожительства на рождаемость вызывает серьезные демографические риски при дальнейшем распространении сожительства, которое особенно усиливаются в свете перспективы сползания России в демографическую яму. Кроме того, это хотя и главный, но не единственный недостаток сожительства.

Плюсы сожительства, заключающиеся в возможности проверить молодым людям свои отношения, примерить социальные роли мужа / жены при относительной про- 
стоте вступления и выхода из этого союза, одновременно могут рассматриваться и как серьезные минусы. Сохранение определенной автономии от ответственности и обязательств семейной жизни может переноситься в дальнейшем на последующие брачные отношения. Относительная простота вступления и выхода из сожительства также имеет свои негативные последствия на институт брака, что и подтверждается официальной статистикой расторжения браков, показатели которой в последние годы держатся на стабильно высоком уровне (2013 г. - 54,5\%, 2015 г. — 52,7\%, 2016 г. $61,7 \%$ (Российский статистический ... , 2017)), несмотря на то что почти каждый третий брачный союз заключается после проверки отношений в сожительстве (Осипова, 2013). Тем самым сожительство недостаточно эффективно выполняет основную роль, которую отводит ему молодое поколение.

Итак, широкое распространение добрачного сожительства не привело к повышению стабильности института брака, что должно найти отражение в государственной социальной политике, в которой все отчетливее артикулируется необходимость воссоздания традиционных семейно-брачных ценностей и формулируется зарегистрированный брак с несколькими детьми в качестве социальной нормы (пока, как мы показали, не повлиявшая на закрепление добрачного сожительства в качестве неформальной нормы), но практически не рассматривается добрачное поведение молодежи. Поэтому ему необходимо уделить особое внимание в процессе воспитания подрастающего поколения и формирования у него нормативных представлений о семейнобрачных отношениях и добрачном поведении.

\section{ЗАКАЮЧЕНИЕ}

Анализ динамики отношения московской молодежи к сожительству позволяет сделать несколько выводов, уточняющих некоторые аспекты данной проблематики. Во-первых, социальная установка на брак у молодежи сохраняется, но нормативная модель брачного поведения изменилась: предваряющее брак сожительство закрепилось в восприятии молодого поколения как неотъемлемая составляющая брачного поведения, а треть респондентов уже имеют подобный опыт. Во-вторых, несмотря на утверждение добрачного сожительства молодежи в качестве социальной нормы, определенная дифференциация отношения к нему, хотя и уменьшается по ряду оснований (половозрастным и религиозным), все еще сохраняется. В-третьих, в межпоколенном восприятии сожительства как нормы или отклонения позиция представителей молодого поколения определяется позицией их родителей, которая дифференцируется в зависимости от пола их ребенка (гораздо более либеральное отношение к сожительству родителей юношей, нежели девушек). В-четвертых, в молодежной среде значительно усилилась установка на рождение ребенка исключительно в браке, а не в сожительстве.

\section{СПИСОК АИТЕРАТУРЫ}

Вот какие мы - россияне. Об итогах Всероссийской переписи населения 2010 года (2011) [Электронный ресурс] // Российская газета - Федеральный выпуск №5660 (284). 22 декабря. URL: https://rg.ru/2011/12/16/stat.html (дата обращения: 02.12.2016).

Распоряжение Правительства Российской Федерации от 29 ноября 2014 г. № 2403-р «Основы государственной молодежной политики Российской Федерации на период до 2025 года» (2014) [Электронный ресурс] // Российская газета. 8 декабря. URL: https://rg.ru/2014/ 12/08/molodej-site-dok.html (дата обращения: 05.01.2018). 
Распоряжение Правительства Российской Федерации от 25 августа 2014 г. № 1618-р «Концепция государственной семейной политики в Российской Федерации до 2025 года» (2014) [Электронный ресурс] // Российская газета. 29 августа. URL: https://rg.ru/2014/08/29/semyasite-dok.html (дата обращения: 05.01.2018).

Ауков, В. А., Тихомиров, А. А. (2012) Аобрачные сексуальные отношения молодежи: дилемма социальной нормы и отклонения. М. : ИзА-во Моск. гуманит. ун-та. 188 с.

Микроперепись населения 2015 (2015) [Электронный ресурс] / Росстат. URL: http:// www.gks.ru/free_doc/new_site/population/demo/micro-perepis/finish/micro-perepis.html (дата обращения: 02.12.2016).

Осипова, И. (2013) Гражданские браки: смыслы и отношение [Электронный ресурс]/ ФОМ. 21 сентября. URL: http://fom.ru/blogs/11093 (дата обращения: 02.12.2016).

Российский статистический ежегодник. 2017 (2017) : стат. сб. / Росстат. М. : ИИЦ «Статистика России». 686 с.

Тихомиров, А. А. (2009) Аобрачные сожительства в Москве как новая составляющая матримониального поведения молодежи // Знание. Понимание. Умение. № 3. С. 106-110.

Тихомиров, А. А. (2017) Половая мораль московских студентов: религиозный аспект // Знание. Понимание. Умение. № 2. С. 210-220. DOI: 10.17805/zpu.2017.2.16

Явон, С. В., Кудрявцева, К. А. (2017) Семейно-брачные отношения в Самарской области и Республике Татарстан // Знание. Понимание. Умение. №4. С. 177-187. DOI: 10.17805/zpu. 2017.4.15

Аата поступления: 30.05.2018 2.

THE DYNAMICS OF MOSCOW YOUNG PEOPLE'S ATTITUDE TO COHABITATION

(BASED ON 2009-2017 EMPIRICAL RESEARCH)

D. A. TIKHOMIROV

PLEKHANOV RUSSIAN UNIVERSITY OF ECONOMICS

The article is based on the results of the author's empirical research conducted over the period of 2009-2017. It examines the dynamics of Moscow young people's attitude to cohabitation. It is shown that the marriage mindset among young people is retained, but the marriage model is changing.

Moscow young people's premarital cohabitation is enshrined as a social norm. This is manifested in the liberal attitude of most young people towards it, the mindset on cohabitation prior to marriage and the wide spread of cohabitation $(33 \%$ of the interviewed young people have a cohabitation experience). The author analyses the change in the attitude to cohabitation within different social groups (sex, age and religion). Despite the consolidation of premarital cohabitation of young people as a social norm, there still remains a certain differentiation of the attitude towards it. In the intergenerational perception of cohabitation as a norm or deviation, the position of the representatives of the younger generation is determined by the position of their parents, which differentiates depending on the sex of their child.

Widespread premarital cohabitation does not lead to an increase in the stability of the institution of marriage. It must be reflected in the state social policy, where a growing need is articulated for recreation of traditional family and marriage values, and registered marriage with several children is formulated as a social norm.

Keywords: young people; cohabitation; premarital cohabitation; marriage; social norm; social deviation; Moscow youth

\section{REFERENCES}

Vot kakie my - rossiiane. Ob itogakh Vserossiiskoi perepisi naseleniia 2010 goda (2011). Rossiiskaia gazeta, no. 5660 (284), 22 December [online] Available at: https://rg.ru/2011/12/16/ stat.html (access date: 02.12.2016). (In Russ.).

Rasporiazhenie Pravitel'stva Rossiiskoi Federatsii ot 29 noiabria 2014 g. № 2403-r «Osnovy gosudarstvennoi molodezhnoi politiki Rossiiskoi Federatsii na period do 2025 goda» (2014). Rossiiskaia 
gazeta, 8 December [online] Available at:: https://rg.ru/2014/12/08/molodej-site-dok.html (access date: 05.01.2018). (In Russ.).

Rasporiazhenie Pravitel'stva Rossiiskoi Federatsii ot 25 avgusta 2014 g. № 1618-r «Kontseptsiia gosudarstvennoi semeinoi politiki v Rossiiskoi Federatsii do 2025 goda»(2014). Rossiiskaia gazeta, 29 August [online] Available at: https://rg.ru/2014/08/29/semya-site-dok.html (access date: 05.01.2018). (In Russ.).

Lukov, V. A. and Tikhomirov, D. A. (2012) Dobrachnye seksual'nye otnosheniia molodezhi: dilemma sotsial' noi normy i otkloneniia. Moscow, Izd-vo Mosk. gumanit. un-ta. 188 p. (In Russ.).

Mikroperepis' naseleniia 2015 (2015). Rosstat [online] Available at: http://www.gks.ru/free_doc/ new_site/population/demo/micro-perepis/finish/micro-perepis.html (access date: 02.12.2016). (In Russ.).

Osipova, I. (2013) Grazhdanskie braki: smysly i otnoshenie. FOM, 21 September [online] Available at: http:// fom.ru/blogs/11093 (access date: 02.12.2016). (In Russ.).

Rossiiskii statisticheskii ezhegodnik. 2017 (2017) : stat. sb. Moscow, IITs «Statistika Rossii». 686 p. (In Russ.).

Tikhomirov, D. A. (2009) Dobrachnye sozhitel'stva v Moskve kak novaia sostavliaiushchaia matrimonial'nogo povedeniia molodezhi. Znanie. Ponimanie. Umenie, no. 3, pp. 106-110. (In Russ.).

Tikhomirov, D. A. (2017) Polovaia moral' moskovskikh studentov: religioznyi aspect. Znanie. Ponimanie. Umenie, no. 2, pp. 210-220. DOI: 10.17805/zpu.2017.2.16 (In Russ.).

Iavon, S. V. and Kudriavtseva, K. A. (2017) Semeino-brachnye otnosheniia v Samarskoi oblasti i Respublike Tatarstan. Znanie. Ponimanie. Umenie, no. 4, pp. 177-187. DOI: 10.17805/zpu.2017.4.15 (In Russ.).

Submission date: 30.05 .2018 .

Тихомиров Амитрий Андреевич - кандидат социологических наук, доцент кафедры политологии и социологии Российского экономического университета им. Г. В. Плеханова. Адрес: 117997, Россия, г. Москва, Стремянный пер., 28, корп. 1. Тел.: +7 (495) 958-23-27. Эл. адрес: dat1983@yandex.ru

Tikhomirov Dmitriy Andreyevich, Candidate of Social Sciences, Associate Professor, Department of Political Science and Social Science, Plekhanov Russian University of Economics. Postal address: 28, Bldg. 1, Stremyanny Lane, Moscow, Russian Federation, 117997. Tel.: +7 (495) 958-23-27. E-mail: dat1983@yandex.ru 